\title{
A concepção do aluno nos programas de EJA no Brasil
}

\section{The conception of student in the Young and Adults Education programs in Brazil}

\author{
Maria do Socorro Martins CALHÁU
}

\begin{abstract}
RESUMO
Há por trás de toda idéia de escola uma idéia de aluno que, em grande parte, é responsável pela concepção de seus rituais e conteúdos. Este artigo trata da concepção de aluno que está subjacente às escolas de Educação de Jovens e Adultos (EJA), e sua implicação na prática pedagógica dos professores e demais agentes escolares, considerando: as políticas públicas responsáveis historicamente pela caracterização das ações e iniciativas de oferta de escolas para adultos e a concepção acadêmicocientífica que tem sido responsável pela elaboração de metodologias, conteúdos e ações didático-pedagógicas, cuja natureza é impregnada por uma determinada concepção de infância responsável por muitos dos equívocos que acontecem na educação de jovens e adultos.
\end{abstract}

Palavras-chave: alfabetização de jovens e adultos, metodologia, prática pedagógica.

\begin{abstract}
Behind any idea of school there is a prior idea of student mostly determinant of teaching rituals and contents. This paper analyzes the concept of student subjacent to adult schools in Brazil and its consequences to the practices of teachers and another school agents, considering: local public policies historically responsible for the character of actions and initiatives related to school's offers for adults and, the academic / scientific background adopted for giving support to methodologies, contents and didactic actions, whose nature, pregnant of certain childhood conception, has been responsible for some of the several equivoques in adult basic education.
\end{abstract}

Index Terms: academic/scientific background, adult schools, methodologies. 
Há por trás de toda idéia de escola uma concepção de aluno que, em grande parte, tem sido responsável pela concepção de seus rituais e conteúdos. Uma idéia, por vezes, equivocada, uma concepção que desconhece a vida real dos sujeitos sociais que buscam a escola na idade adulta. Esse artigo trata da concepção de aluno que está subjacente às escolas de Educação de Jovens e Adultos (EJA), e sua implicação na prática pedagógica dos professores e demais agentes escolares. Para que se possa compreender a representação escolar de aluno que se encontra presente nas escolas de EJA, é necessário realizar uma complexa análise. Esse artigo refletirá sobre duas vertentes importantes e constitutivas dessa concepção. A primeira é a vertente política, responsável, historicamente, pela caracterização das ações e iniciativas de oferta de escolas para adultos. A segunda é a vertente acadêmico-científica responsável pela elaboração de metodologias, conteúdos e ações que pressupõem um sujeito cognoscente "idealizado" que não se enquadra à realidade dos alunos jovens e adultos que buscam as escolas de EJA. Além disso, esse trabalho também faz saber que esta última vertente é impregnada de uma determinada concepção de infância responsável por muitos dos equívocos pedagógicos que acontecem na educação de jovens e adultos.

Para que se possa compreender melhor a questão política é necessário entender que as idéias de carência e de falta foram, em grande parte, responsáveis pela criação de escolas para adultos. Nascidas de inúmeras campanhas e movimentos salvacionistas, as escolas de adultos, até pouquíssimo tempo, eram chamadas de escolas supletivas e tratavam apenas da alfabetização. Fávero (2004), que vive essa história há muitos anos, esclarece que apesar da discussão sobre a escolarização dos adultos no Brasil existir desde a Colônia e o Império, é somente a partir da década de 1940 que o analfabetismo começa a ser tratado como um problema nacional, preocupando e mobilizando o poder público. 
Esse fato deriva de uma série de acontecimentos que provocam o Estado a uma tomada de posição. Segundo Fávero (2004), em meados da década de 1940, há dois fatores importantes influindo na preocupação com a educação de adultos: o momento pós-ditadura que trás uma onda de redemocratização ao país e a criação da Organização das Nações Unidas para a Educação, a Ciência e a Cultura (Unesco), ao final da Segunda Guerra Mundial.

É precisamente em 1947 que a União lança a Campanha de Educação de Adolescentes e Adultos (CEAA). Fávero (2004) esclarece que:

[...] embora suas ações tenham praticamente se restringido à alfabetização, sua proposta visava a uma ação educativa ampla, compreendendo a aprendizagem da leitura e da escrita, as operações elementares do cálculo, as noções básicas de cidadania, higiene e saúde, geografia e história pátria, puericultura e economia doméstica para as mulheres. (FÁVERO, 2004, p. 14-15)

As ações da Unesco, assim como todas aquelas que foram motivadas por ela, estavam impregnadas de uma idéia de educação para a América Latina, uma idéia meramente compensatória de cunho assistencialista e de conteúdo preconceituoso em relação ao analfabeto adulto. Concebidas dessa forma, essas ações, de cunho assistencialista não reconheciam a educação de adultos como direito. O não reconhecimento do direito à educação para as pessoas jovens e adultas aliado à idéia de compensação, são, entre outros, responsáveis por uma idéia de aluno muito equivocada, que tem estado presente na maior parte das escolas de EJA há dezenas de anos.

$\mathrm{Na}$ realidade, já se sabia, nessa época, que o motivo de existir adultos analfabetos era a inexistência ou a pouca eficácia de escolas primárias para as crianças das classes populares. É no seio dessa discussão que surge a idéia de "ação supletiva" do Estado. Fávero (2004) complementa dizendo que esta ação visava

[...] atender aos não escolarizados, supondo sua inserção na vida produtiva industrial e na vida cívica urbana, ou para viabilizar, por intermédio dos instrumentos de divulgação cultural, a continuidade da aplicação e a atualização 
de conhecimentos aprendidos na precária escolarização. (FÁVERO, 2004, p. 16)

As campanhas de "combate" ao analfabetismo aconteceram até o final dos anos de 1950, quando a discussão em relação à elaboração da primeira Lei de Diretrizes e Bases da Educação Nacional (LBDN), têm início. A partir daí foram inúmeras as discussões dos técnicos do Ministério da Educação e Cultura (MEC) e do Instituto Nacional de Estudos e Pesquisas Educacionais Anísio Teixeira (Inep) com o objetivo de reestruturar todo o sistema municipal de ensino e regularizar a matrícula das crianças entre 7 e 10 anos. Além disso, no centro dessas discussões, foram criadas as "classes de emergência" para os adolescentes que não tiveram acesso ou que tinham sido postos fora da escola, e também organizaram classes de alfabetização para os jovens e adultos.

Por essa ocasião era forte a tendência nacionalista que assolava o país. Foi também nesse período que se realizou o II Congresso Nacional de Educação de Adultos, que teve como um de seus relatores Paulo Freire. Foi nessa época que o entendimento do analfabetismo passa por uma radical transformação. Os relatórios do II Congresso Nacional chamavam a atenção, pela primeira vez, para o analfabetismo, que não se devia a uma "inferioridade intrínseca" do analfabeto, mas entendendo que se tratava de um problema sócio-econômico, motivado pela desigualdade e pela injustiça social, que necessitava ser enfrentado definitivamente.

Aqui cabe uma reflexão que só foi feita muitos anos depois desses acontecimentos. Apesar do imenso ganho que se caracterizou pela nova abordagem do analfabetismo como um problema político-social,e da prática alfabetizadora ganhar um forte acento na conscientização e na cultura desse aluno, pouco se avançou na questão metodológica da aquisição da língua escrita, stricto sensu.

Não se tratava mais do aluno inferior em sua capacidade cognitiva, ele também não deveria ser visto como uma "vergonha nacional", embora 
essa idéia nunca tenha deixado de habitar o imaginário dos adultos não alfabetizados, tamanha a força com a qual foi disseminada. Tratava-se, pois, de educar alguém que era portador de outra cultura, que deveria ser conscientizado de seu papel político na sociedade. Uma idéia que poderia ser muito interessante não fosse pelo fato de que esse papel era definido pelos intelectuais de classe média; membros da igreja católica; e demais segmentos que sonhavam e lutavam por uma transformação política, de cunho socialista no país. Um sonho que foi desmantelado pelo golpe militar em 1964.

Durante a ditadura militar perdem-se os avanços conquistados na década de 1960, varrem-se do país todas as experiências que estavam em curso, e pior, retrocede-se a uma idéia de analfabetismo como inferioridade e doença que precisa ser erradicada para o progresso da nação.

Desta forma, mesmo decorridos muitos anos desse período, e embora vivendo há mais de 30 anos numa sociedade democrática, os jovens e adultos alunos da escola de EJA trazem consigo uma enorme baixa-estima e uma forte sensação de serem totalmente rejeitados pela cultura letrada, da qual a escola é legítima representante. A recíproca dessa afirmação também é verdadeira, uma vez que a escola pensa esse aluno como alguém que não se enquadra aos seus rituais.

O sentimento de rejeição pela cultura letrada é o segundo aspecto que necessita ser discutido quando se deseja compreender melhor a idéia de aluno presente nas escolas de EJA. Oriundos de uma realidade social e cultural totalmente desprestigiada, os alunos jovens e adultos não reconhecem a escola como um local de pertencimento e acolhimento. Mesmo assim, esses sujeitos sociais atribuem à escola o poder de transformar suas vidas e, por esse motivo, buscam-na e permanecem nela por algum tempo, na tentativa de estabelecer um vínculo possível. Vivendo nesse conflito entre a realidade da escola e a sua realidade sócio-cultural eles ficam divididos. É evidente que esses jovens e adultos são muito mais 
susceptíveis aos movimentos culturais de suas comunidades do que à sua vida escolar. Sendo assim, dificilmente conseguem desenvolver pela escola um sentimento de total pertencimento, conforme desejavam. Refletindo sobre o assunto Senna (2003) afirma que:

\begin{abstract}
[...] as circunstâncias sociais extra-escolares que definem o modelo cultural dos jovens brasileiros, particularmente os oriundos das grandes massas de cidadãos em estado de exclusão e marginalização, tendem a competir, com vantagem, contra a escola, especialmente por imputar aos alunos um sentimento de não pertencimento à sociedade alfabetizada. (SENNA, 2003, p. 2)
\end{abstract}

Senna (2004) quando reflete sobre a educação, na perspectiva da inclusão, afirma que a Razão científica se instituiu como a única unidade cultural, em detrimento de todas as outras. Decorre daí que os jovens e adultos que buscam a escolarização tardia passam pela escola com um forte sentimento de estranhamento aos seus rituais, ao mesmo tempo em que só reconhecem essa escola se ela corresponder a uma idéia bastante tradicional e disciplinadora que trazem desde a infância. Desta forma, a escola, como espaço privilegiado dessa Razão, vê os sujeitos não escolarizados como pessoas incapazes. Essa visão de aluno encontra sentido em antigas questões disseminadas há muito tempo e que até hoje habitam o imaginário de alunos e professores. Ele afirma que:

[...] ainda é muito forte em nosso imaginário o princípio sintetizado no dito popular em que se declara 'ser preciso ir à escola para ser gente na vida,' aludindo-se, assim, aos não escolarizados como não-gentes, como sujeitos desprovidos de Razão, como os outros. (SENNA, 2003, p. 54)

Em relação à cultura científica, ou cultura letrada, a idéia de aluno se confunde com o próprio analfabetismo. O analfabetismo é caracterizado como vergonha e incapacidade, fazendo com que os adultos não alfabetizados assumam para si a culpa e a consequiência de seu "não saber ler", sentindo-se como incapazes, doentes e inferiores, em relação aos outros e ao país. A idéia de "erradicação" toma conta das discussões, e analfabetismo e analfabeto se (com)fundem como objeto da extinção 
(CALHÁU, 2005, p. 2). É importante não se perder de vista, nesse momento, que a concepção de aluno que se desenvolve nas escolas é fortemente influenciada pelo seu objeto de aprendizagem, no caso da EJA, a leitura e a escrita.

Numa sociedade como a brasileira onde existe uma grande variedade lingüística, os falantes costumam ter o mesmo valor que o seu falar, ou seja, como os lugares sociais são diferenciados, o prestígio lingüístico está associado ao prestígio social dos falantes (GNERRE, 1991) Não é à toa que, de maneira geral, observa-se grande dificuldade no aprendizado da escrita e posteriormente no seu uso pelos jovens e adultos alfabetizados. Alguns pesquisadores da história da alfabetização nas sociedades afirmam que muitos são os questionamentos sobre o valor da escrita por parte de algumas culturas e até mesmo por teóricos da história da civilização.

Lévi-Strauss (1975) a partir do seu trabalho com tribos indígenas brasileiras afirma que a palavra escrita é um modo de exercício do poder que ao surgir favorece mais a dominação e a exploração dos homens que a sua iluminação. A função da comunicação em sua opinião é facilitar a servidão. Outras tribos, como a dos samoanos, possuem grande desconfiança em relação à escrita, já que ela não é concreta como a comunicação face a face. Para eles, a utilização da palavra escrita pelo homem é percebida como uma renúncia de si próprio para aderir ao texto, a uma outra lógica de crenças e valores (SCHEURMANN, 2003).

Também é fato que na história do desenvolvimento humano, a transição da oralidade para a escrita aconteceu num rico e profundo processo de interação. Desta forma, a educação clássica e outras formas de educação permaneceram, por muito tempo, como atividades orais. As palavras escritas e impressas posteriormente eram difundidas através de processos orais. A própria leitura era uma atividade oral, freqüentemente partilhada, e não a atividade privada e silenciosa que conhecemos hoje (CHARTIER, 1991). 
Apesar da história nos mostrar todo o rico percurso da oralidade e sua benéfica influência na construção da escrita, a escola, quando ensina a ler e escrever, não se orienta pela tradição oral de seus alunos. Pior, trabalha com um modelo de escrita que não fala ao desejo nem à realidade dos alunos da EJA e tampouco às suas necessidades. O texto escolar é, na maioria das vezes, frio e fora da realidade na qual vivem esses sujeitos sociais. A leitura e a escrita escolares se fundam mais na decifração do código do que na produção de sentidos. O texto acaba sendo trabalhado apenas como pretexto para o ensino da gramática, conjunto de normas que não estão presentes na oralidade, deixando de fora a grande aventura que realmente deveria ser ler e escrever enquanto possibilidade de conhecer ou divulgar novos mundos reais ou imaginários (LERNER, 1996).

O resultado disso é o grande desconforto dos alunos frente a uma folha em branco ao longo de sua escolarização. A possibilidade de produção de um texto, ao invés de desafiá-los, faz com que fiquem assustados, paralisados, amedrontados (CALHÁU, 1997). Assim, não se sentem à vontade para se apropriar da escrita, uma vez que escrever pressupõe uma decisão de registrar, revelar seu pensamento, expor seu ponto de vista, seu sentimento, de modo que ele possa se tornar visível e até público. Quem escreve cria condições para que a sua palavra ganhe permanência. Nessa perspectiva a escrita pressupõe uma reescrita e esse refazer se dá num processo onde o autor transita entre a reflexão e a impulsão. É nessa dinâmica que sua sensibilidade e condições de apreensão da realidade vão se ampliando (BEZERRA, 1999).

Não podemos nos esquecer que a maior parte dos professores que hoje atuam na EJA, foram, no passado, esses alunos que saíram da escola entendendo a escrita como uma inimiga e não como uma possibilidade de comunicação e expressão; tampouco a identificam como instrumento de superação da realidade em que vivem. 
À luz do que foi exposto até aqui, é fácil observar como a dinâmica da recente história política, que motivou os projetos educacionais no Brasil, associada à vocação de uma ciência que se acredita como a única possibilidade de inclusão dos sujeitos em um mundo legitimado e prestigiado, foram produzindo uma idéia de analfabeto ou de adulto pouco escolarizado que tem vigorado até os dias de hoje, dentro e fora das escolas da EJA.

Embora tenha sido criada para incluir os sujeitos que não puderam estudar na chamada "idade apropriada", a escola de EJA, em grande parte, não reconhece a sociedade brasileira como sendo eminentemente oral, desconhece o valor e a riqueza da oralidade, e quando a utiliza no processo de aprendizagem da escrita, o faz de forma estereotipada e caricaturada, assim como procede com a imensa diversidade cultural da qual os alunos jovens e adultos são representantes.

Além disso, é importante salientar o quanto essa concepção de aluno está impregnada por uma idéia de infância. Uma concepção de infância vinculada à idéia de carência, falta, incompletude. Uma idéia de infância que pensa os processos educativos como algo que vai funcionar como um exercício de poder dos adultos sobre as crianças no sentido de tornarem-nas submissas às regras de um mundo adultocêntrico (LEAL, 2004).

A idéia de delimitar e categorizar períodos e abrangências para a sua clientela tem servido à escola muito mais à dominação do que à emancipação de seus alunos. Seja centrada num mundo infantil ou num universo adulto, a concepção de aluno vai ser sempre limitada se não for realizada uma reflexão muito mais ampla sobre a função da educação em uma sociedade complexa como a que se tem hoje, principalmente no Brasil. Refletindo sobre as categorias de infância e vida adulta Kohan (1999) nos diz que:

[...] não há crianças por natureza. Tampouco há adultos por natureza. Esta categorização social está acompanhada de práticas, saberes e valores que constituem 
identidades, enquadram relações interpessoais e delimitam modos de vida. (KOHAN, 1999, p. 62)

Diante da análise dessas duas vertentes surge claramente uma idéia de aluno que pouco tem servido à construção de uma escola realmente inclusiva. Menos ainda de uma escola que possa ser instrumento de transformação social. $\mathrm{O}$ enfrentamento das questões educacionais relativas ao aluno da EJA, sua inclusão e seu sucesso na cultura letrada, não encontram eco na realidade que é vivenciada dentro das escolas. Há um estranhamento histórico, político, científico e cultural que impede a inclusão e a utilização da escola como espaço de emancipação e construção de alternativas para a problemática social da injustiça e da desigualdade. Impede, sobretudo, que se pense a alfabetização e a escolarização tardia como possibilidade de recriação e de potencialização de práticas já desenvolvidas por esses sujeitos sociais que há muito tempo convivem em sua cultura com outras alternativas e estratégias de sobrevivência na vida diária e no trabalho.

Embora os pesquisadores da história da alfabetização (GRAFF, 1990; FRAGO, 1993), coloquem em dúvida as conseqüências da aquisição da alfabetização no progresso das sociedades, é preciso ter em mente que o analfabetismo enquanto dimensão da pobreza só diminui e dificulta a vida de um povo que precisa migrar para a cidade grande, eminentemente grafocêntrica, em busca de uma "melhor qualidade" de vida. Trata-se, portanto, de uma questão de direito.

Mesmo diante dessas constatações e, sobretudo, diante da visão que os jovens e adultos não alfabetizados possuem de si mesmos, é preciso ter clareza de que o analfabetismo tem várias acepções, e que os alunos que buscam a escola de EJA, embora não saibam ler nem escrever, em grande parte são alfabetizados no que diz respeito ao trabalho: na construção civil, no campo, na agricultura, na pecuária. É na escola, trabalhando com esses 
sujeitos que se constata que todas as pessoas podem ser analfabetas em alguns temas e alfabetizadas em outros, como nos diz Frago (1993):

Analfabeto é pois, também, em um sentido figurado mais amplo, aquele que desconhece ou não sabe nada sobre um tema determinado. 'Sou um analfabeto em matéria de carros' (leia-se condução ou 'mecânica do automóvel') ou 'és um analfabeto em questões da bolsa' são frases que indicam um desconhecimento notável sobre um setor ou área de conhecimentos, práticas ou habilidades. O prestígio ou difusão social dos mesmos e o contexto em que são pronunciados é que determinarão o grau de vergonha, própria ou alheia que tais palavras suscitam. (FRAGO, 1993, p. 23)

Para alguns autores, o analfabetismo possui outra interpretação, como no caso da arte-educadora Ostrower (1992):

E veja que absurdo: formam-se anualmente não sei quantos doutores, em medicina, química, engenharia, economia, etc..., que nunca mais irão abrir um livro. Não lêem. Foram alfabetizados, sim, tiveram o privilégio de cursar escolas, mas é uma alfabetização funcional. Culturalmente, não passam de analfabetos. Tecnocratas! Vão saber os mínimos detalhes sobre a rosca de um parafuso, e em sua banalidade interior vão ignorar que há toda uma vida vibrante em torno deles, um mundo riquíssimo de experiências humanas feitas em culturas do passado e do presente. (OSTROWER, 1992, p. 25)

Nesse artigo não estão em discussão os valores e os prazeres que a alfabetização pode ou não trazer, e muito menos se estes trazem poder ou riqueza à uma determinada sociedade. O que precisa ficar claro, no caso do Brasil, é que o analfabetismo, antes de tudo, é um fenômeno de exclusão social e de marginalização econômica, de obrigatório afastamento político e de negação dos benefícios sociais e dos direitos civis (LEWIN, 1990). O que está em discussão é o quanto a escola, em sua concepção preconceituosa e equivocada de aluno, não permite que a aprendizagem aconteça sob uma perspectiva de criação e emancipação. No caso da EJA e seu aprendizado, a leitura e a escrita precisam estar a serviço desses sujeitos sociais, pois são ferramentas poderosas de uma sociedade injusta e desigual que se vale do analfabetismo para prosseguir no atraso de uma dominação perversa. 
Também não se pode acreditar que a alfabetização, por si só, enquanto técnica de decifrar materiais escritos e impressos, possa ser responsável pela transformação de uma sociedade injusta. Tampouco é esse o papel da escolarização básica. Ao contrário, nada substitui a expressão criativa de um grupo social, sua autonomia e a capacidade de traduzir as idéias em ações.

É preciso desmitificar o valor que a escola atribui à leitura e à escrita, pois se não, correremos o risco de fazermos com que o processo de alfabetização seja apenas uma superposição de culturas sem nenhum valor criativo e pouca função social. A alfabetização, do modo como está legitimada em nossa sociedade, se não ocorrer como acesso a um instrumento de explicitação das idéias, pode fazer com que, em nome de ser alfabetizado, haja uma renúncia à criatividade e à espontaneidade de seus adeptos.

Há que se pensar muito sobre a concepção de democracia tão proclamada no processo educativo e também se faz necessário rever a forma como os educadores utilizam-se poder que lhes é conferido, a serviço de um suposto "discurso democrático", que serve muito mais à concepção preconceituosa de aluno, presente nas escolas, do que à formação de sujeitos da cultura letrada. A este respeito, Garcia (1985) afirma que:

A prática é o grande teste de um discurso democrático. Explico. Nunca vi uma prática igualitária, aberta e democrática revestida de um discurso autoritário. Mas já assisti a muito discurso democrático revestido de prática autoritária. Em si mesmos, os discursos podem se equivaler, mas é a prática que vai apontar a fratura de um e a integridade do outro. E esta integridade não é fácil de conseguir numa sociedade hierarquizada, onde a difusão de saberes se dá, fundamentalmente, de cima para baixo. É mesmo um desafio numa relação tão desigual quanto a do analfabeto com o seu professor. (GARCIA, 1985, p. 9) 
A reflexão sobre as práticas escolares, segundo Gnerre (1991), pode não só desvendar a interpretação recíproca que está presente na situação de alfabetização mas superar muitas dificuldades inerentes a ela.

Este artigo refletiu sobre o quanto é possível, através do processo de alfabetização ou de escolarização tardia, reforçar a dependência das pessoas inseguras e há muito espoliadas, ou ao contrário, possibilitar que elas percebam, assumam e relativizem as causas de seu analfabetismo e de sua exclusão social e serem os sujeitos de sua transformação, condição sem a qual essa transformação não acontece.

Fica a certeza de que ninguém transforma ninguém e que, em certo sentido, para que se possa transformar essas concepções de aluno em um ideário inclusivo, há que se ter certa disponibilidade interna, a escola por meio de seus professores; e os alunos, para compreender e transformar as crenças sobre si próprios e sobre os outros. É necessário, sobretudo, num processo de alfabetização, no âmbito de uma instituição escolar, refletir sobre o valor que atribuem à educação, à alfabetização e, principalmente, aos alunos da EJA. A este respeito vale ouvir Gnerre (1991) quando afirma:

[...] nós os interpretamos e ao seu mundo, projetamos sobre eles a nossa perspectiva profundamente letrada e grafocêntrica do nosso mundo sócio-cultural. Eles nos interpretam como portadores de valores diferentes ou, no mínimo, de uma técnica e de um saber que eles por uma razão ou outra não controlam. (GNERRE, 1991, p. 46)

E aqui cabe à escola e seus agentes compreender os motivos que os levam a pensar a educação de um único ponto de vista, de um paradigma estritamente ligado à racionalidade moderna. Só será possível transformar os rituais escolares e as ideologias que se encontram subjacentes a eles, no momento em que for realizada uma cuidadosa análise sobre quais os conhecimentos que podem ser reconhecidos como verdadeiros. Essa reflexão vai definir, de uma vez por todas, quem são os excluídos. Já é hora de transformar essa visão de ciência e de verdade. Não há mais lugar para uma razão científica que não reconhece a complexidade dos fenômenos 
mentais e a pluralidade de contextos históricos e culturais que permeiam toda a sociedade (MORIN, 1999; VYGOTSKY, 1991).

Na opinião de Senna (2004), as reflexões atuais sobre complexidade, pluralização das verdades, contexto histórico, devem produzir um efeito bastante positivo na constituição de uma educação inclusiva. A escola e seus agentes precisam tomar consciência de um novo paradigma que admite a existência de variáveis conceituais historicamente determinadas, que possam orientar as novas produções de conhecimento acadêmico-científico para que, enfim, seja possível realizar um diálogo com a diversidade cultural existente.

O percurso atual da educação inclusiva não pode desprezar o fato de que a situação dos incluídos nos sistemas de escolarização formal está diretamente vinculada ao processo de ruptura com os dogmas com que a cultura científica definiu - para si e para a escola - o conceito de verdade. (SENNA, 2004, p. 58)

E, finalmente, é necessário compreender que a escola de EJA não pode ser concebida à luz das escolas infantis, tampouco, numa perspectiva de falta ou de carência. É necessário que essas escolas sejam capazes de compreender e admitir a possibilidade de existência de outros saberes, de outras possibilidades, de outras estratégias, de outras linguagens capazes de registrar e divulgar a expressão criativa de um determinado grupo social. Acima de tudo, a escola de jovens e adultos precisa realizar uma reflexão sobre o verdadeiro valor da leitura e da escrita numa sociedade que está totalmente permeada por ela e nem por isso incólume aos problemas como a violência, a guerra, a intolerância, a fome, a miséria, entre outras. A escola de EJA necessita ser, antes tudo, um espaço de fortalecimento de um grupo social que tem sido vítima da exclusão, do preconceito e, acima de tudo, de uma política de negação dos direitos. 


\section{Referências bibliográficas}

BEZERRA, Aída (1999). Divagações Sobre a Paixão de Ler e Escrever. Cadernos BAM. Rio de Janeiro: SAPÉ/DPH/FNDE/SEF/MEC.

CALHÁU, Maria do Socorro M. (2005). Educação de jovens e Adultos: história e memória. Documentário Especial Salto Para o Futuro, TVE, Rio de Janeiro: MEC/SECAD.

CALHÁU, Maria do Socorro M.; AGUIAR, Alexandre (1997). O que é o BAM. Revista Alfabetização e Cidadania - RAAAB, São Paulo, n. 5, jul., 1997.

CHARTIER, Roger (1991). As Práticas de Escrita. In: ARIÈS, Phillipe et al. História da vida privada. São Paulo: Companhia das Letras. p. 113161.

FÁVERO, Osmar. Lições de História: os avanços de sessenta anos e a relação com as políticas de negação de direitos que alimentam as condições de analfabetismo no Brasil. In: Oliveira, Inês Barbosa \& Paiva, Jane (orgs). Educação de Jovens e Adultos. Coleção O sentido da Escola. Rio de Janeiro: DP\&A 2004. pp. 13-28.

FRAGO, Antonio Vinão (1993). Alfabetização na sociedade e na história: vozes, palavras e textos. Porto Alegre: Editora Artes Médicas.

GARCIA, Pedro Benjamim (1985). O Olho de Outro: algumas anotações sobre alfabetização de adultos. In: GARCIA, Pedro et al. 3. ed. Cadernos de Educação Popular, n. 8. Petrópolis: Editora Vozes/Nova - Pesquisa e Assessoria em Educação. p. 9-18.

GNERRE, Maurizio (1991). Linguagem, Escrita e Poder. São Paulo: Editora Martins Fontes.

GRAFF, Harvey J. (1990). O Mito do Alfabetismo. Tradução Tomaz Tadeu da Silva. Teoria e Educação, São Paulo, n. 2, p. 31-64.

KOHAN, Walter Omar (1999). Filosofia e infância: Pontos de Encontro. In: KOHAN, Walter Omar; KENNED, David. Filosofia e Infância: possibilidade de um encontro. Petrópolis, RJ: Editora Vozes.

LEAL, Bernardina (2004). Leituras da Infância na poesia de Manoel de Barros. In: KOHAN, Walter Omar (Org.). Lugares da Infância. Rio de Janeiro: DP\&A Editora. 
LERNER, Délia (1996). Es possible leer en la escuela? SEMINÁRIO INTERNACIONAL DA ESCOLA DA VILA. Rio de Janeiro, maio, 1996. Mimeo.

LÉVI-STRAUSS, Claude (1975). Tristes Trópicos. Portugal: Edições Setenta.

LEWIN, Helena (1990). O adulto analfabeto na América Latina. In: GARCIA, Pedro et al. Cadernos de Educação Popular, n. 17. Petrópolis, RJ: Vozes/Nova.

MORIN, Edgar (1999). Por uma Reforma do Pensamento. In: PENAVEGA, Alfredo; NASCIMENTO, Elimar Pinheiro do. O Pensar Complexo: Edgar Morin e a crise da modernidade. Rio de Janeiro: Editora Garamount.

OLIVEIRA, Inês Barbosa; PAIVA, Jane (Orgs.) (2004). Educação de Jovens e Adultos. Rio de Janeiro: DP\&A Editora.

OSTROWER, Fayga (1992). A aventura do aprender e do saber. PROPOSTAIFASE, Rio de Janeiro, n. 52.

SENNA, Luiz Antonio Gomes (2004). De Vygotsky a Morin: entre dois fundamentos da educação inclusiva. Informativo Técnico-Científico Espaço (Ines), Rio de Janeiro, n. 22, jul./dez., p. 53-58.

(2003). O Planejamento no Ensino Básico \& o compromisso social da educação com o Letramento. Educação \& Linguagem, São José dos Campos, n. 7, p. 200-216.

SCHEURMANN, Erich (2003). O Papalagui: comentários recolhidos por Erich Scheurmann. São Paulo: Editora Marco Zero.

VYGOTSKY, Lev Semenovich (1991). A formação social da mente. 4. ed. São Paulo: Editora Martins Fontes. 


\section{Autora}

\section{Maria do Socorro Martins CALHÁU}

Mestre em Educação pela Pontifícia Universidade Católica do Rio de Janeiro (PUC/RJ) e Doutoranda em Educação pela Universidade do Estado do Rio de Janeiro (UERJ). Coordenadora Pedagógica do Núcleo de Educação de Adultos (Nead) da PUC/RJ.

mscalhau@edu.puc-rio.br

\section{Como citar este artigo:}

CALHÁU, Maria do Socorro Martins. A concepção do aluno nos programas de EJA no Brasil. Revista ACOALFAplp: Acolhendo a Alfabetização nos Países de Língua portuguesa, São Paulo, ano 2, n. 3, 2007. Disponível em: <http://www.mocambras.org> e ou <http://www.acoalfaplp.org>. Publicado em: setembro 2007. 